\title{
Morphological Characterisation of Diesel Soot in oil and the Associated Extraction Dependence
}

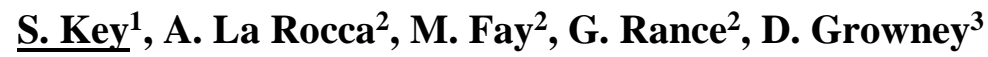 \\ ${ }^{1}$ Associate, University of Nottingham. ${ }^{2}$ University of Nottingham. ${ }^{3}$ Lubrizol Ltd.
}

\begin{abstract}
The size and morphology of soot particles and agglomerates extracted from lubricating oil drawn from the sump of a diesel engine have been investigated and compared using Transmission Electron Microscopy (TEM) and Nanoparticle Tracking Analysis (NTA). Samples were prepared for electron microscopy imaging by both centrifugation and solvent extraction to investigate the impact of these procedures on the morphological characteristics, such as skeleton length and width and circularity, of the obtained soot. It was shown that centrifugation increases the extent of agglomeration within the sample, with $15 \%$ of the agglomerates above $200 \mathrm{~nm}$ compared to only $11 \%$ in the solvent extracted soot. It was also observed that the width of centrifugation extracted soot was typically $10 \mathrm{~nm}$ to $20 \mathrm{~nm}$ larger than that of solvent extracted soot, suggesting that centrifugation forces the individual agglomerate chains together. Moreover, centrifugation fails to extract a large percentage of particles below $50 \mathrm{~nm}$, with only $4 \%$ of the agglomerates smaller than $50 \mathrm{~nm}$ in the centrifugation extracted soot, whereas agglomerates in this size range accounted for $19 \%$ using solvent extraction. As TEM represents a comparatively time and cost expensive characterisation tool, unsuitable for high throughput testing required by industry, NTA was explored as a low cost, rapid alternative method for measuring particle size. It was found that results generated by NTA, within the limits of detection, correlated well with those obtained using TEM. This correlative electron microscopy and light scattering approach was further used to appraise the morphological characteristics of two commercial sources of carbon black (CB), enabling the selection of the most suitable soot surrogate, essential for the further development of oils with optimised functional properties.
\end{abstract}

\section{INTRODUCTION}

The majority of carbonaceous matter produced by incomplete combustion in a diesel engine is ejected from the system within the exhaust gases. However, a small fraction is forced past the piston rings post-ignition, via blow-by gases, into the oil sump or transferred to the oil film on the cylinder liner via thermophoresis. Recent diesel engine design changes have been developed to meet increasingly stringent emissions requirements. Technologies such as EGR (Exhaust Gas Recirculation) have been introduced to reduce the level of emissions released. However, this technology promotes soot formation and increases the amount of soot in the oil. The contamination of lubricating oil by diesel soot is considered one of the major causes of Page 1 of 8 engine wear $[1,2]$. However, the relationship between soot contamination of oil and wear, friction and oil viscosity, is complex, as noted by a large number of authors [3-17]. Of particular interest is the impact of the size and morphology of the soot agglomerates on oil viscosity and wear of metal engine parts. The valve train can be particularly vulnerable to wear $[4,5]$ as it has been suggested that the hardness of soot nanoparticles can abrade metallic surfaces [6,7]. The particle surface area and its reactivity can also have an impact on wear, as well as the properties of soot-laden oil [8-10]. Moreover, the interaction of soot particles with dispersant additives also impacts on friction and is known to be dependent on the particle morphology $[11,12]$.

Transmission Electron Microscopy (TEM) has been widely used to study the size distribution and morphology of soot in oil [13-16]. Chinas-Castillo et al. [7] linked the observed abrasive wear to the size of the primary particles. The small primary particles adhere to the surfaces influencing friction and wear; this is particularly pronounced at low contact speeds when the particle size is greater than the lubrication film. Patel et al. [16] investigated the morphology of both extracted diesel soot and a carbon black (CB) analogue and found the size of the primary soot particle to be $20 \mathrm{~nm}$ to $30 \mathrm{~nm}$. La Rocca et al. [13] noted that diesel soot agglomerates extracted from used engine oil can be found as either long chain-like particles or in more compact cluster-like shapes. As TEM requires soot to be extracted from the used oil to avoid contamination and imaging issues under the electron beam, centrifugation is often employed, with variations on the method used by Clague et al. [3] seen throughout literature. However, questions have been raised recently concerning the effect of centrifugation on agglomerate size distribution [13]. It has been suggested that centrifugation modifies the size distribution and shape of soot agglomerates, by forcing the individual agglomerate chains together, without altering the size of primary particles. Yet, the extent of this problem is not clear at present as the use of dispersant may help to overcome this artificial agglomeration during centrifugation. Moreover, La Rocca et al. suggested that centrifugation is not necessary for TEM measurements of soot agglomerate size, and that the solvent extraction method sufficiently removes the contaminating oil from the soot [15].

Issues of lengthy sample preparation and extensive data analysis, often taking several days per sample measured, make TEM analysis of soot a time consuming and expensive technique. Furthermore, large uncertainties have been recently reported in 2D-measured morphological parameters, such as the radius of gyration and the fractal dimension of soot agglomerates [18], related to the 
approximation and correction factors intrinsically embedded in the calculation of such parameters, as well as the imaging of two dimensional projections of three-dimensional structures. Circularity, defined as a function of area and perimeter, does not require use of correction factors [19] and will be used in this study to characterise the geometrical features of soot agglomerates. The high throughput testing required by industry would benefit from a less onerous characterisation tool. Nanoparticle Tracking Analysis (NTA) has been proposed by La Rocca et al. as an alternative method to measure the size distribution of diesel soot in oil $[14,17]$. The technique is widely used in medical, pharmaceutical and toxicological applications due to its experimental simplicity and high quality and reproducibility of results [20]. Data acquisition can be as short as ten seconds per sample compared to typically three hours needed for TEM image acquisition. NTA measures the hydrodynamic diameter of soot agglomerates and it has been suggested that this parameter correlates well with agglomerate skeleton length determined by TEM [17] and thus warrants further investigation.

Engine oil manufacturers use soot-laden oils to test the effectiveness of additives, including dispersants. However, genuine soot-laden oil samples are expensive to generate, and so carbon black is often used as a surrogate. Carbon black is significantly cheaper than genuine engine soot and can be produced on a much larger scale. However, as carbon black is produced in a different way to genuine soot, there is potential for key compositional and structural differences. To ensure a good model surrogate for soot, it is essential to elucidate the nature of these differences, often done by comparison of the size of the primary particle and the size distribution and shape of agglomerates dispersed in a solvent or additised oil [3]. Growney et al. [21] and Clague et al. [3] compared carbon black to diesel soot and discussed its suitability as a model colloidal surrogate, finding similarities in areas such as particle size.

The purpose of this work is to determine the effect of centrifugation on soot agglomerate size, and whether the solvent extraction procedure proposed in [15] avoids this issue. This will involve comparative analysis of the soot samples isolated by the two extraction procedures, namely centrifugation and solvent extraction, by both TEM and NTA. Furthermore, two carbon black surrogate materials supplied by Lubrizol Ltd will be analysed in an analogous fashion to identify the most suitable simulant of engine soot.

\section{EXPERIMENTAL SETUP AND SAMPLE PREPARATION}

The oil samples used in this study were drawn from the sump of an OM646LA diesel engine. This engine was selected as it is representative of the typical diesel engine technology. The fully formulated oil used was a 5W-20 oil containing an olefin copolymer dispersant. The engine was operated following a 300 hour CEC L-9908 test program, which is typically used to evaluate oil performance with regard to wear. At the end of the 300 hour period, the oil sample was drawn from the sump for the investigation of the soot content.

\section{Transmission Electron Microscopy}

TEM was used to assess the size of primary soot particles and the size distribution and morphology of soot agglomerates extracted from engine oil. However, as engine oil itself complicates imaging by TEM, representing an undesired contaminant that is often unstable under the electron beam, suitable sample preparation was required to remove any

Page 2 of 8 lubricant present on the surface of the soot. To achieve this, two techniques, referred to as "centrifugation extraction" and "solvent extraction", were compared. In the centrifugation extraction approach, the soot-laden oil samples were diluted with $n$-heptane $(30 \mathrm{ml})$, before being subjected to centrifugation for 8 hours at $6,000 \mathrm{rpm}\left(20^{\circ} \mathrm{C}\right)$. The soot was subsequently washed with hexane twice to remove remaining oil. In the solvent extraction approach, the used oil was diluted with $n$ heptane to give a final dilution of 20,000. In addition, two commercial carbon black samples purchased from Cabot, CB A and CB B (5 g each), were dispersed in a fully formulated fresh oil ( $95 \mathrm{~g}$ ) containing the same oil and additive package as in the drain oil and left for six weeks to allow the particle size distributions to equilibrate. Solvent extraction was then used to remove the oil from the carbon black surface.

The cleaned soot and carbon black samples were separately drop cast onto copper-mounted carbon films (graphene oxide on holey amorphous carbon, EM Resolutions) and the residual $n$-heptane removed by evaporation under ambient conditions. Images were acquired using a JEOL 2100F FEG-TEM, equipped with a Gatan Orius SC1000 CCD camera (Nanoscale and Microscale Research Centre, University of Nottingham). For each sample, exactly 100 particles or agglomerates, selected as representative of the bulk soot in oil samples, were measured using open architecture imaging software ImageJ. The skeleton length and width, $\mathrm{L}_{\mathrm{sk}}$ and $\mathrm{W}_{\mathrm{sk}}$ respectively (Figure 1), were measured as described by La Rocca et al. [13].
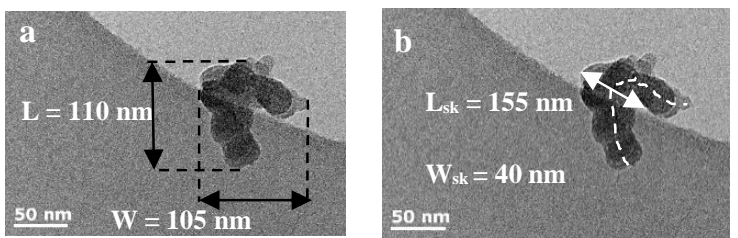

Figure 1. (a) TEM image of soot particle, sized using $\mathrm{L}$ and $\mathrm{W}$ measurements. (b) TEM image of soot particle, sized using $\mathrm{L}_{\mathrm{sk}}$ and $\mathrm{W}_{\mathrm{sk}}$ measurements.

Whilst length and width measurements can be made of soot agglomerates (Figure 1a), this measurement method neglects the fact that soot agglomerates are very rarely space filling within their external dimensions, possessing more branched structures, often with gaps within the structures that are not accounted for. Measuring skeleton length and width (Figure 1b) overcomes this issue and provides a better representation of the morphology of the agglomerate.

\section{Nanoparticle Tracking Analysis}

Nanoparticle Tracking Analysis (NTA) is a novel technique aimed at real-time and direct analysis of nanoparticles in liquid suspensions, superior to complementary light scattering approaches, such as dynamic light scattering, for multimodal particle size distributions, such as those typically found in soot in oil dispersions [20]. NTA can rapidly size soot nanoparticles within a diluted oil sample and is comprised of three basic steps: (i) video capture, (ii) setting of analysis parameters and (iii) tracking analysis. In each measurement, a narrow laser beam $(\lambda=405 \mathrm{~nm})$ is passed through the nanoparticle-containing dispersion and the light scattered from the particles as they move under Brownian motion recorded as a video at 30 frames per second typically. The subsequent analysis is performed directly on the particles observed in the video, tracking the translation of each scattering centre individually over time. The analysis stops when the 
particle has moved out of the field of view, out of the plane of focus or has crossed the path of another particle. The hydrodynamic diameter of the tracked particles is calculated using the Stokes-Einstein equation:

$d_{h}=\frac{K_{B} T t_{s}}{3 \pi \eta D}$

where $D$ is the particle mean square displacement, $K_{B}$ is the Boltzmann's constant, $T$ is the temperature in Kelvin, $t_{s}$ is the sampling time in seconds, $\eta$ is the viscosity of the continuous phase and $d_{h}$ is the hydrodynamic diameter of the tracked particle. The high viscosity of the oil in the as-received samples inhibits the motion of particles on a measureable timescale and thus prevents the particle size being determined. As a consequence, samples were initially diluted in $n$ heptane. To achieve a suitable concentration, the samples were serially diluted to give a final dilution of 100,000 for the drain oil, 20,000 for the centrifugation extracted soot re-dispersed in fresh oil, 100,000 for CB A dispersed in fresh oil and 10,000 for CB B dispersed in fresh oil. All samples were dispersed in $n$-heptane by gentle agitation.

For each measurement, the dispersion of soot in $n$-heptane $(1 \mathrm{ml})$ was injected into the sample chamber of the Malvern Nanosight LM14 (Nanoscale and Microscale Research Centre, University of Nottingham) using a glass syringe. The laser was turned on and an area of the sample where nanoparticles were best illuminated was brought into focus manually. A series of three 30 second automated captures at $20^{\circ} \mathrm{C}$ was performed, producing a total of 900 frames per sample. The data was analysed using NTA V3.2 software. The reference value of viscosity used in this study is $0.4 \mathrm{mPa}$ s and at the dilution ratios used, the effect of the oil viscosity is low and can therefore be disregarded. Attention was paid to ensure the particle concentration was between $10^{5}-10^{10}$ particles/ml as suggested by Malloy and Carr [20]. This was to ensure there are enough particles for a robust size distribution to be generated, but not so many as to increase the overlap between particles and therefore invalidate a large number of tracks.

\section{RESULTS AND DISCUSSION}

Differences in the structure and morphology of soot particles isolated by the centrifugation-extraction and solvent-extraction methods was appraised by TEM (Figures 2 and 3 respectively) and statistically treated (Figure 4 and Table 1).
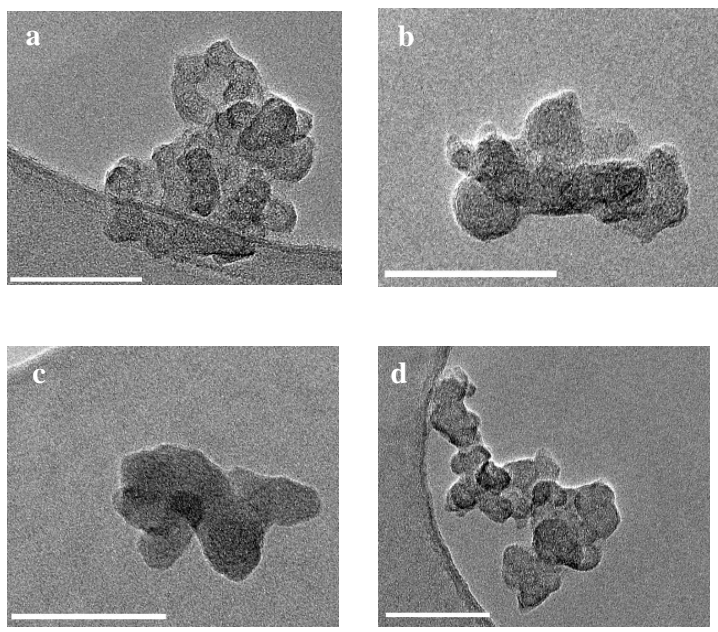

Figure 2. Representative TEM images of centrifugation-extracted soot after sonication in heptane for 10 minutes with agglomerates in the size range (a)(c) $35-240 \mathrm{~nm}$ and (d) above $400 \mathrm{~nm}$. Scale bars are $100 \mathrm{~nm}$.
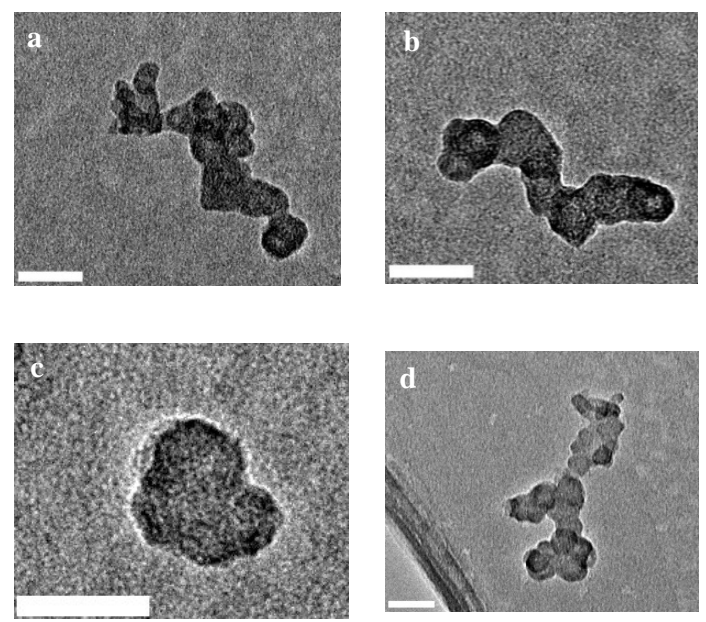

Figure 3. Representative TEM images of solvent-extracted soot agglomerates in the size range (a)-(c) $20-185 \mathrm{~nm}$ and (d) above $400 \mathrm{~nm}$. Scale bars are 50 $\mathrm{nm}$.

The micrographs in Figure 2 illustrate typical soot agglomerates found in the centrifugation-extracted soot sample after sonication in $n$ heptane for 10 minutes, and possess a clustered structure, typically falling into the size range $35-250 \mathrm{~nm}$ (Figure 2a-c), with some larger agglomerates above $300 \mathrm{~nm}$ also observed (Figure 2d). By comparison, the soot isolated using the solvent-extraction method seen in Figure 3 appears to be in smaller agglomerates, with a greater proportion appearing more "chain-like" compared to the clusters seen for the centrifugation-extracted soot. The agglomerates were typically in the size range 20-185 $\mathrm{nm}$ (Figure 3a-c), with a large number of monodisperse primary particles observed. Analogous to the centrifugation-extracted soot, some large agglomerates above $200 \mathrm{~nm}$ were additionally present (Figure 3d). 

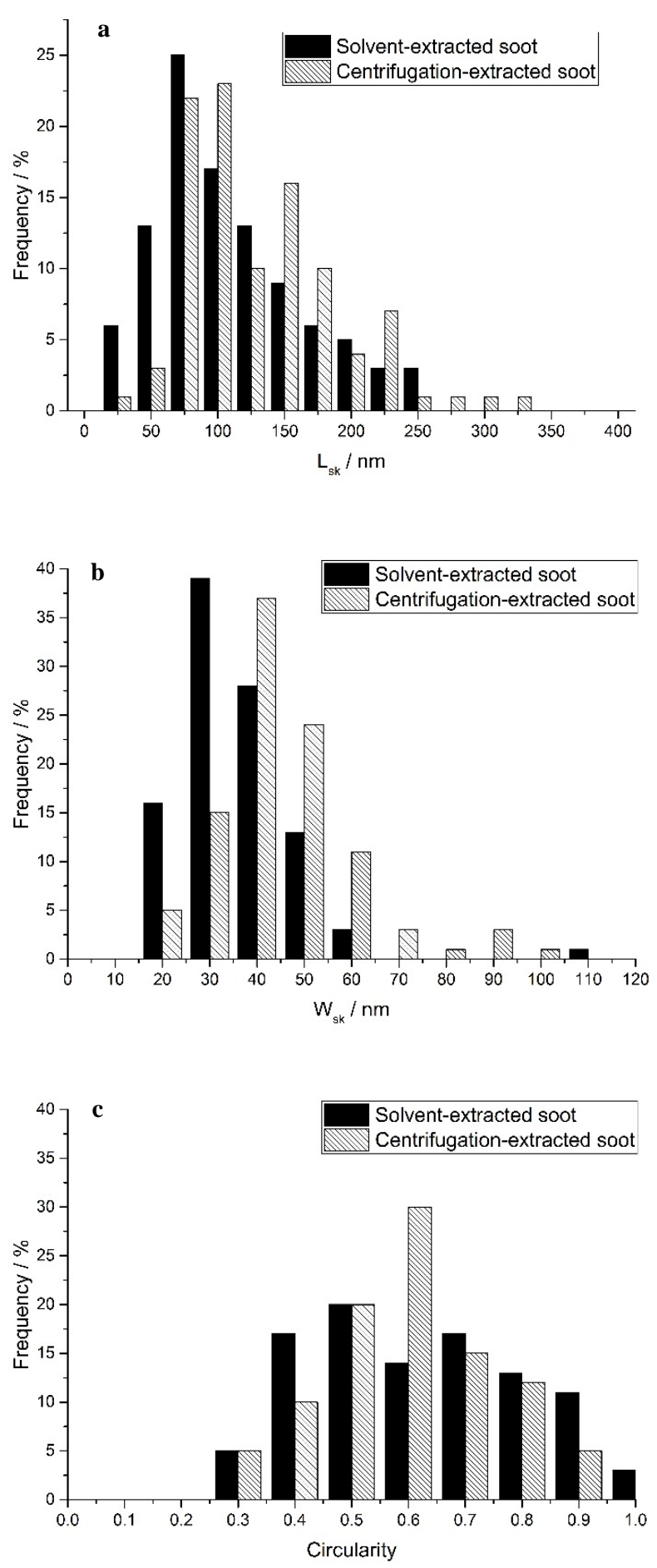

Figure 4. Histograms displaying the range of (a) $\mathrm{L}_{\mathrm{sk}}$, (b) $\mathrm{W}_{\mathrm{sk}}$, and (c) circularity values obtained by statistical treatment of TEM images of soot isolated by both solvent- and centrifugation-extraction methods.

The skeleton length, $\mathrm{L}_{\mathrm{sk}}$, and width, $\mathrm{W}_{\mathrm{sk}}$, was measured for each sample (Figure $4 \mathrm{a}$ and $\mathrm{b}$ respectively). It was found that $19 \%$ of the solvent-extracted soot possessed a skeleton length $50 \mathrm{~nm}$ or less, whereas this only makes up $4 \%$ of the centrifugation-extracted soot

Page 4 of 8 sample. This suggests that smaller and better dispersed particles have not been removed by centrifugation, instead remaining in the supernatant fluid. Moreover, the solvent-extracted soot contains $11 \%$ of agglomerates equal to or above $200 \mathrm{~nm}$, whereas the centrifugationextracted soot contains $15 \%$ at this size, indicating that centrifugation causes a shift towards higher agglomerate sizes, potentially as a sideeffect of the centrifugation process, which could force smaller agglomerates together. Furthermore, the maximum $\mathrm{L}_{\text {sk }}$ observed in the centrifugation-extracted sample is almost $100 \mathrm{~nm}$ higher than that seen in the solvent-extracted analogue, similarly suggesting a higher level of agglomeration for soot extracted by centrifugation.

The minimum $\mathrm{W}_{\mathrm{sk}}$ values were 11 and $14 \mathrm{~nm}$ for the solvent-extracted and centrifugation-extracted samples respectively, which can be attributed to the smaller primary particles (Figure 4b). As the two soot samples are from the same drain, the primary particles should be approximately equal, and so any changes in the width will be due to aggregation with the agglomerates building up from one primary particle wide. Furthermore, the mean $\mathrm{W}_{\mathrm{sk}}$ of the centrifugationextracted sample is approximately $10 \mathrm{~nm}$ higher than that of the solvent-extracted material. As the primary particles were found to have a mean value of $24 \mathrm{~nm}$, this suggests that the solvent-extracted sample contains many chains with a width of one primary particle, whereas the centrifugation-extracted sample has a larger proportion of chains around two primary particles wide. This provides further evidence that centrifugation forces individual chain-like agglomerates together during this purification procedure.

The aspect ratio, $\mathrm{L}_{\mathrm{sk}} / \mathrm{W}_{\mathrm{sk}}$, was calculated and the proportion of clusters $\left(\mathrm{L}_{\mathrm{sk}} / \mathrm{W}_{\mathrm{sk}}>2.5\right)$ and chain-like agglomerates $\left(\mathrm{L}_{\mathrm{sk}} / \mathrm{W}_{\mathrm{sk}} \leq 2.5\right)$ in the two soot samples compared (Table 1). From this analysis, it was observed that the solvent-extracted sample contained $39 \%$ clusters and $61 \%$ chain-like agglomerates, whereas the centrifugation-extracted sample contained 36 and $64 \%$ respectively, thus indicating little difference in the type and shape of agglomerates between samples. However, it is important to note that this analysis cannot differentiate between a "long and wide" agglomerate and a "short and narrow" agglomerate possessing identical aspect ratios. The findings from this analysis (Figures $4 \mathrm{a}, \mathrm{b}$ and Table 1 ) suggests that while both $\mathrm{L}_{\mathrm{sk}}$ and $\mathrm{W}_{\text {sk }}$ change as a function of the purification procedure, the aspect ratio is relatively unaffected.

Circularity is a shape factor function of the perimeter and the area defined as $4 \pi\left(\right.$ area/perimeter $\left.{ }^{2}\right)$ - with a value of 1 describing the particle as a circle, whilst a value approaching 0 indicates that the perimeter of the particle is more irregular [19]. From statistical analysis of circularity (Figure 4c), it was found that $14 \%$ of agglomerates possessed a circularity value of 0.9 or above in the solvent-extracted soot, whereas in the centrifugation-extracted soot, this was only $8 \%$. It was observed that particles with a circularity of 0.9 or above were generally primary particles, suggesting that the solvent-extracted soot contained a higher proportion of monodispersed primary particles. 
Table 1. Statistical analysis of the morphological characteristics of extracted soot and carbon black particles and agglomerates obtained by TEM imaging.

\begin{tabular}{|c|c|c|c|c|c|c|c|c|c|c|c|c|}
\hline \multirow[t]{2}{*}{ Sample } & \multicolumn{3}{|c|}{ Skeleton length, $\mathbf{L}_{\mathrm{sk}} / \mathbf{n m}$} & \multicolumn{3}{|c|}{ Skeleton width, $W_{\text {sk }} / \mathbf{n m}$} & \multicolumn{3}{|c|}{$\begin{array}{l}\text { Ratio of skeleton length to } \\
\text { width, } L_{s k} / W_{s k}\end{array}$} & \multicolumn{3}{|c|}{ Circularity } \\
\hline & Mean & Mode & Range & Mean & Mode & Range & Mean & Mode & Range & Mean & Mode & Range \\
\hline $\begin{array}{l}\text { Centrifugation } \\
\text { extracted soot }\end{array}$ & $112 \pm 59$ & 100 & $41-314$ & $40 \pm 15$ & 40 & 14-94 & $3.0 \pm 1.2$ & 3.5 & $1.2-6.5$ & $0.56 \pm 0.16$ & 0.6 & $0.25-0.98$ \\
\hline $\begin{array}{c}\text { Solvent } \\
\text { extracted soot }\end{array}$ & $95 \pm 54$ & 75 & $20-241$ & $30 \pm 13$ & 30 & 11-106 & $3.1 \pm 1.4$ & 2 & $1.3-7.3$ & $0.57 \pm 0.18$ & 0.5 & $0.26-0.92$ \\
\hline $\mathrm{CB} \mathrm{A}$ & $154 \pm 114$ & 75 & $41-562$ & $62 \pm 28$ & 50 & $24-169$ & $2.4 \pm 1.1$ & 2.5 & $1.1-7.2$ & $0.70 \pm 0.19$ & 0.7 & $0.22-0.98$ \\
\hline CB B & $149 \pm 86$ & 100 & $21-405$ & $46 \pm 20$ & 40 & $18-122$ & $3.2 \pm 1.4$ & 3 & $1.1-8.1$ & $0.53 \pm 0.18$ & $0.6,0.7$ & $0.19-0.95$ \\
\hline
\end{tabular}

For NTA to be a viable alternative to TEM, it must support the observations obtained by this advanced microscopy approach. NTA was used to study soot within drain oil and centrifugation-extracted soot re-dispersed back into fresh fully formulated oil to assess whether soot isolated by centrifugation affects the size of the agglomerates and whether it is representative of soot found within the drain oil. Up to 7,500 particles were measured per sample by NTA, compared to only 100 by TEM image analysis, thus ensuring greater statistical significance. The absolute intensity of light scattered from the particles under observation was noted and found to represent only soot particles, and not metal particles occasionally introduced into the oil during engine wear [20]. Interestingly, the NTA results for the drain oil were found to correlate well with results of solvent-extracted soot generated by TEM, with mean particle sizes of 95 and $96.5 \mathrm{~nm}$ obtained by TEM and NTA respectively (Figure 5). The maximum value obtained by NTA is $450 \mathrm{~nm}$ which is larger than that expected from analysis by TEM; however, this represents a very small contribution $(<0.1 \%)$ to the total size distribution.

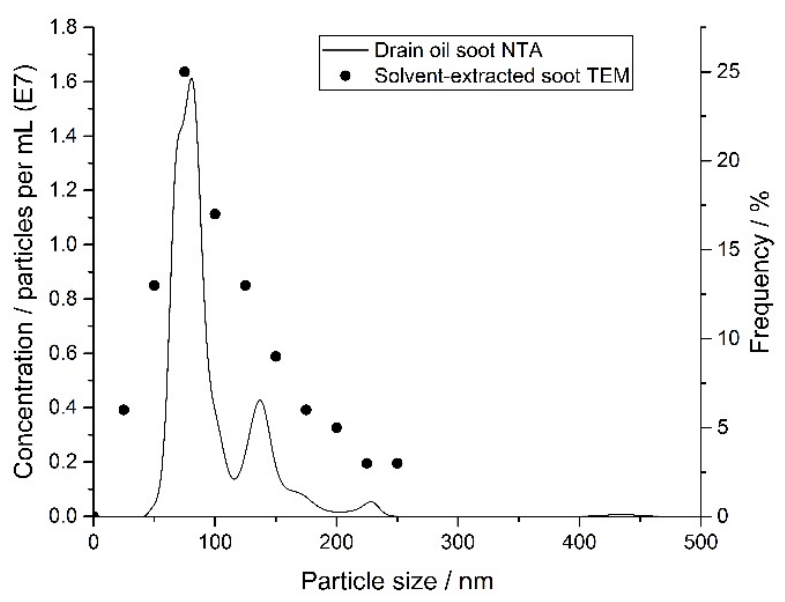

Figure 5. Concentration of particles against size (as hydrodynamic diameter) obtained by NTA for soot isolated from both drain oil and frequency of particles against particle size (as skeleton length) obtained by TEM for solvent-extracted soot. A small number of particles greater than $300 \mathrm{~nm}$ are measured by NTA.

The drain oil and centrifugation-extracted soot in oil both contained most of the agglomerates between 60 and $250 \mathrm{~nm}$ by NTA (Figure 6 ). The mean diameter in the drain oil is $96.5 \mathrm{~nm}$, compared to $115.3 \mathrm{~nm}$ in the centrifugation-extracted soot sample. This is a difference of

Page 5 of 8 approximately $20 \mathrm{~nm}$ which is close to the average size of a primary soot particle. This again suggests that centrifugation forces together individual chains to form larger agglomerates. The drain oil sample contained $2.3 \%$ of agglomerates above $200 \mathrm{~nm}$, whereas the centrifugation-extracted soot contains $7.3 \%$ in this size range. This correlates well with TEM results, with centrifugation-extracted soot containing a higher level of large agglomerates than drain oil or solvent-extracted soot. An advantage of NTA is that the centrifugation-extracted soot can be directly compared to a drain oil, and so removing any uncertainty associated with comparing to an alternately extracted soot. Figure 6 shows that although the centrifugation-extracted soot had been in contact with dispersant in a fully formulated oil, this had not resulted in the soot returning to the size distribution found within the drain oil.

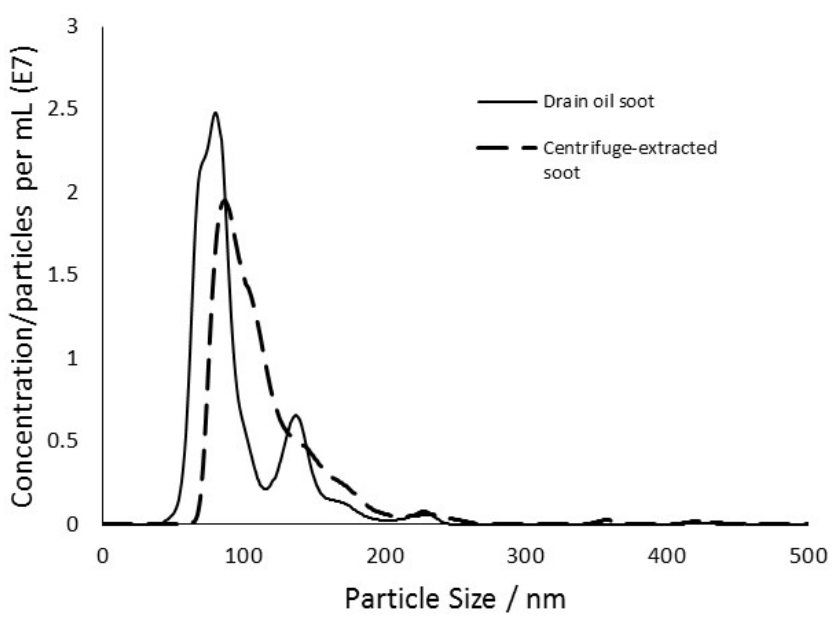

Figure 6. Frequency against hydrodynamic diameter, $d_{h}$, obtained by NTA for drain oil and centrifugation-extracted soot.

This correlative microscopy and light scattering approach has shown that centrifugation promotes the agglomeration of soot, resulting in larger agglomerates. Centrifugation also fails to remove a proportion of the smallest and best dispersed particles, reducing the number of monodispersed particles in the resultant soot sample. Interestingly, treatment of the sample in an ultrasonic bath $\left(10\right.$ minutes, $\left.25{ }^{\circ} \mathrm{C}\right)$ did not return it to the composition of the solvent-extracted soot. 
Therefore, the comparison of carbon black will be made to solventextracted soot.

TEM analysis of the carbon blacks indicates that agglomerates are found in both carbon black (CB) A and B (Figure 7 and Table 1).

CB A
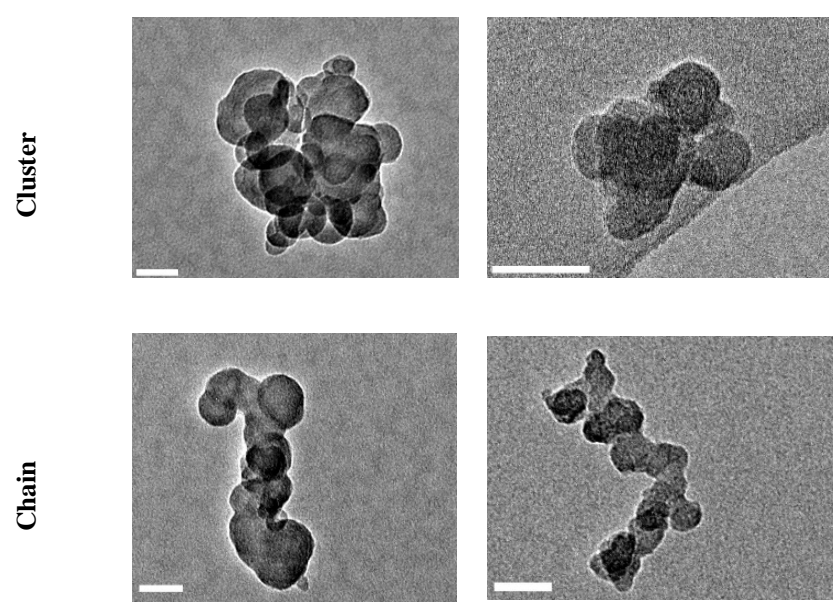

Figure 7. Example TEM images of CB A and B extracted by solvent extraction. Scale bars are $50 \mathrm{~nm}$.

Primary particles were measured from TEM images of engine soot and the two carbon blacks (Figure 8). Mean particle sizes were determined to be $24 \mathrm{~nm}$ for genuine soot, $49 \mathrm{~nm}$ for CB A and $25 \mathrm{~nm}$ for CB B. A standard deviation of $1.60 \mathrm{~nm}$ was obtained for $\mathrm{CB} A, 0.63 \mathrm{~nm}$ for $\mathrm{CB}$ $\mathrm{B}$ and $0.71 \mathrm{~nm}$ for soot. Soot and $\mathrm{CB} B$ have a more narrow range of sizes than $\mathrm{CB} A$, suggesting that $\mathrm{CB} B$ is a better mimic for soot than CB A.

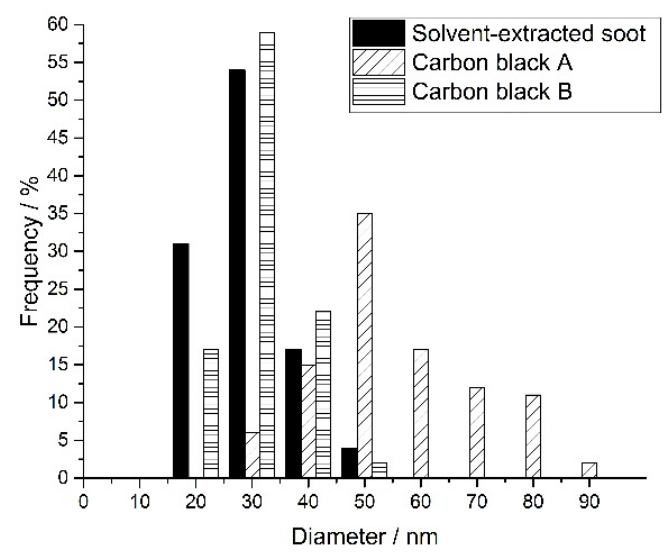

Figure 8. Distribution of primary particle sizes, comparison between engine soot, $\mathrm{CB}$ A and $\mathrm{CB} B$.

Statistical analysis of the obtained TEM images (Figure 9a) indicates that, in terms of $\mathrm{L}_{\mathrm{sk}}$, both the carbon blacks have fewer agglomerates less than or equal to $75 \mathrm{~nm}$ than the soot, with this size range making up $44 \%$ of the soot sample, $23 \%$ of the CB A sample and $17 \%$ of the Page 6 of 8
CB B sample. Agglomerates $250 \mathrm{~nm}$ and above comprise $3 \%$ of the soot sample, $15 \%$ of CB A and $21 \%$ of CB B, meaning that both carbon blacks have agglomerated to a greater extent than the soot.

Although the modal values of $\mathrm{CB}$ A and soot are the same, CB B resembles soot more in terms of the range of sizes. $\mathrm{CB} A$ also has a greater spread of sizes $(\mathrm{StD}=114 \mathrm{~nm})$ than both soot $(\mathrm{StD}=54 \mathrm{~nm})$ and $\mathrm{CB} B(\mathrm{StD}=86 \mathrm{~nm})$.

Width analysis (Figure 9b) indicates that agglomerates with $\mathrm{W}_{\mathrm{sk}}$ less than or equal to $40 \mathrm{~nm}$ made up $83 \%$ of agglomerates in the soot sample, $16 \%$ of CB A and $49 \%$ of CB B. This lack of agglomerates below $40 \mathrm{~nm}$ in the carbon black materials is due to the primary particle size being higher than that of the soot, specifically in CB A. The soot contained only $3 \%$ of agglomerates at $60 \mathrm{~nm}$ or above, compared to CB A containing $63 \%$ and CB B containing $34 \%$. This suggests that both carbon black materials agglomerate to a greater extent than the soot; however, this is more prevalent in $\mathrm{CB} \mathrm{A}$. CB A has a greater spread of widths $(\mathrm{StD}=28 \mathrm{~nm})$, with $\mathrm{CB} B(\mathrm{StD}=20 \mathrm{~nm})$ being more similar to soot $(\mathrm{StD}=13 \mathrm{~nm})$ in this respect.

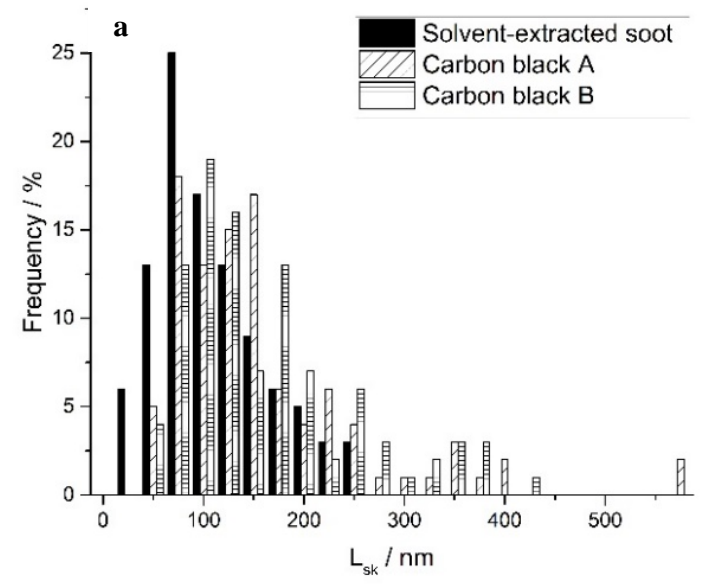

Figure 9a. Histograms displaying the range of skeleton length $\left(\mathrm{L}_{\mathrm{sk}}\right)$ values obtained by statistical treatment of TEM images of solvent-extracted soot, CB $\mathrm{A}$ and $\mathrm{CB} \mathrm{B}$.

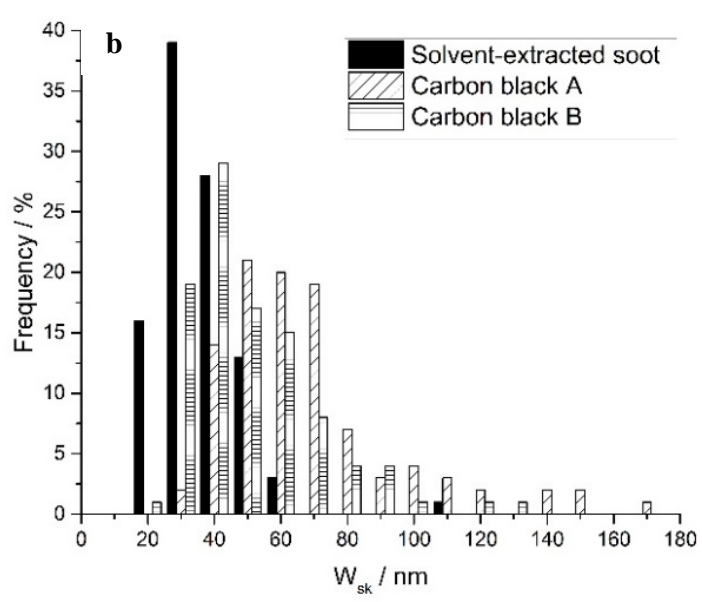

Figure 9b. Histograms displaying the range of skeleton width $\left(\mathrm{W}_{\mathrm{sk}}\right)$ values obtained by statistical treatment of TEM images of solvent-extracted soot, CB $\mathrm{A}$ and $\mathrm{CB} \mathrm{B}$. 


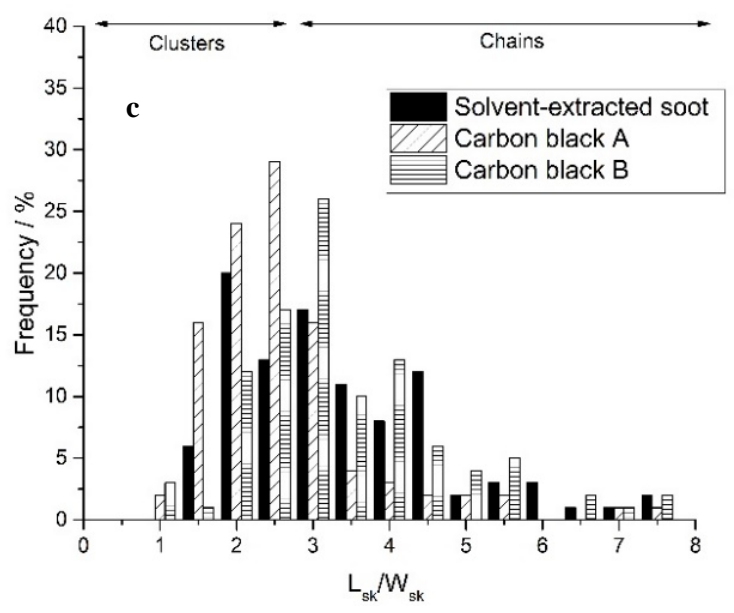

Figure 9c. Histograms displaying the range of $\mathrm{L}_{\mathrm{sk}} / \mathrm{W}_{\mathrm{sk}}$ values obtained by statistical treatment of TEM images of solvent-extracted soot, CB A and CB B.

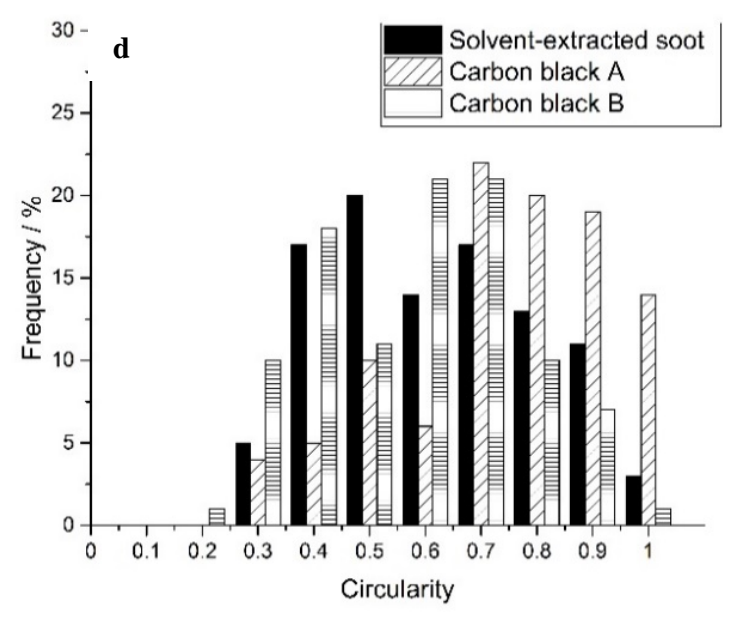

Figure 9d. Histograms displaying the range of circularity values obtained by statistical treatment of TEM images of solvent-extracted soot, $\mathrm{CB}$ A and CB B.

Aspect ratio analysis (Figure 9c) shows that the soot contained $39 \%$ clusters and $61 \%$ chain-like agglomerates; in contrast, CB A contained $71 \%$ clusters and $29 \%$ chains and CB B was more soot-like with 33 $\%$ clusters and $67 \%$ chains. This provides a clear difference between the carbon blacks, with $\mathrm{CB} B$ resembling soot to a much greater extent than CB A.

In terms of circularity (Figure 9d), it is clear that $14 \%$ of soot agglomerates, $33 \%$ of CB A and $8 \%$ of CB B had a circularity of 0.9 or above. This suggests that $\mathrm{CB} A$ contains a higher proportion of monodisperse particles than both soot and $\mathrm{CB} B$, which were quite similar.

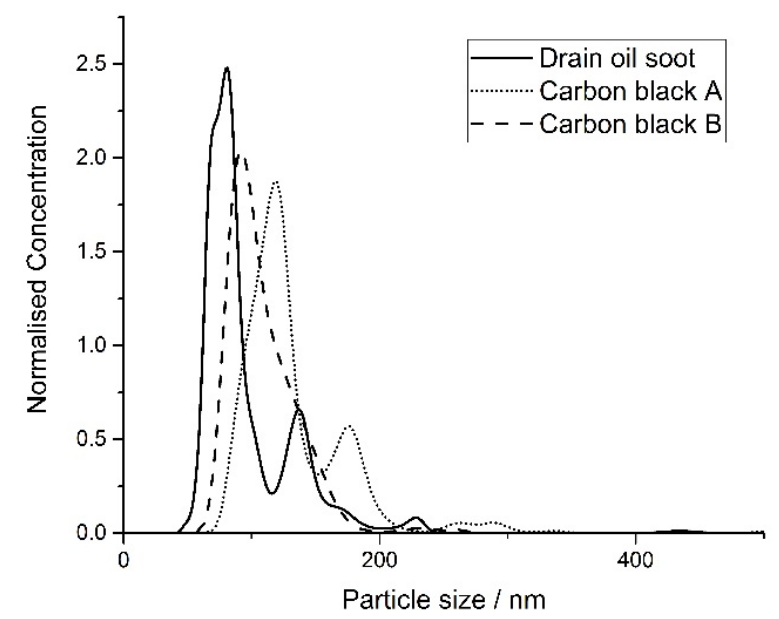

Figure 10. Frequency against hydrodynamic diameter, $d_{h}$, obtained from NTA measurements of engine soot, $\mathrm{CB}$ A and CB B. Concentration is normalized dividing raw data by total number of particle analysed per sample.

By NTA, the mean hydrodynamic diameters of soot, CB A and B were $96.5,116.8$ and $91.8 \mathrm{~nm}$ respectively (Figure 10). CB A contains 5.1 $\%$ of particles with a diameter of $200 \mathrm{~nm}$ or above, whereas CB B contains $1.2 \%$ and the drain oil contains $2.3 \%$, meaning CB B is more similar to soot in this respect. These results are in agreement with TEM, and so CB B was concluded to be the better mimic for soot.

\section{CONCLUSIONS}

Solvent extraction is the recommended method for the extraction of soot from a used oil. The majority of centrifugation-extracted soot was found to fall in the range $35-240 \mathrm{~nm}$, compared to solvent-extracted soot between 20-185 nm. Centrifugation fails to remove the smallest and most well dispersed particles and agglomerates. It also causes the soot to agglomerate to a greater extent than is seen within the used drain oil. NTA is a suitable method to estimate the particle size distribution of soot agglomerates from soot-laden oil samples, and is in good agreement with size distributions obtained by TEM image analysis. However, NTA cannot detect scatter from soot particles below approximately $50 \mathrm{~nm}$, and so cannot be used to determine the size of primary particles. Both techniques concluded that $\mathrm{CB} B$ was a better mimic than $\mathrm{CB}$ A for the genuine diesel soot.

\section{REFERENCES}

[1] Berbezier I. et al., "The role of carbon in lubricated mild wear", France: Butterworth \& CO Ltd, Tribology International, 1986.

[2] Green, D.A., Lewis, R., Dwyer-Joyce, R.S., "Wear effects and mechanisms of soot-contaminated automotive lubricants", Proc I. Mech. E. -J Engineering 220(J3), 159-169, 2006.

[3] Clague, A.D.H., Donnet, J., Wang, T.K. Peng, J.C.M., "A comparison of diesel engine soot with carbon black", Carbon 37(10) 1553-1565, 1999.

[4] Mainwaring, R., "Soot and wear in heavy duty diesel engines", Additives' 97 - Additives in Petroleum Refinery and Petroleum Product Formulation Practice, Proceedings 128-147, 1997. 
[5] Nagai, I., Endo, H., Nakamura, H., and Yano, H., "Soot and Valve Train Wear in Passenger Car Diesel Engines," SAE Technical Paper 831757, 1983, https://doi.org/10.4271/831757.

[6] Gautam, M., Durbha, M., Chitoor, K., Jaraiedi, M. et al., "Contribution of Soot Contaminated Oils to Wear," SAE Technical Paper 981406, 1998, https://doi.org/10.4271/981406.

[7] Chinas-Castillo, F., Spikes, H.A., "The behavior of diluted sooted oils in lubricated contacts", Tribol Lett 16(4), 317-322, 2004.

[8] Antusch, S., Dienwiebel, M., Nold, E., Albers, P., et. al., "On the tribochemical action of engine soot", Wear 269(1), 1-12, 2010.

[9] Corso, S. and Adamo, R., "The Effect of Diesel Soot on Reactivity of Oil Additives and Valve Train Materials," SAE Technical Paper 841369, 1984, https://doi.org/10.4271/841369.

[10] Hu, E., Hu, X., Liu, T., Fang, L., et.al., "The role of soot particles in the tribological behavior of engine lubricating oils", Wear 304(1), 152-161, 2013.

[11] Rounds F.G., "Base Oil Effects on Fatigue Life for Additive Blends as Measured on a 4-Ball Fatigue Machine”, ASLE Trans 20(2), 115-125, 1977.

[12] Xu, X., Sun, S., Wang, P., Lei, A., et.al., "Study on Tribology Performance of Diesel Engine Oil Using SRV4 Tribometer", Tribology Online 10(2), 172-176 2015.

[13] La Rocca, A., Di Liberto, G., Shayler P. J., Fay, M. W. "The nanostructure of soot in oil particles and agglomerates from an automotive diesel engine," Tribology International, 61,80-87, 2013. [14] La Rocca, A., Di Liberto, G., Shayler, P. J., Parmenter C. D. J., et.al., "Application of nanoparticle tracking analysis platform for the measurement of soot in oil agglomerates from automotive engines",

Tribology International ,70,142-147, 2014.

[15] La Rocca, A., Bonatesta, F., Fay, M. W., Campanella F.,

"Characterisation of soot in oil from a gasoline direct injection engine using Transmission Electron Microscopy" (2015) Tribology International, 86, 77-84

[16] Patel, M., "Morphology, structure and chemistry of extracted diesel soot-Part I: Transmission electron microscopy, Raman spectroscopy, X-ray photoelectron spectroscopy and synchrotron Xray diffraction study," Tribology International, 52, 29-39, 2012.

[17] La Rocca, A., Di Liberto, G., Shayler, P., Parmenter, C. et al.,

"A Novel Diagnostics Tool for Measuring Soot Agglomerates Size

Distribution in Used Automotive Lubricant Oils," SAE Int. J. Fuels

Lubr. 7(1):301-306, 2014, https://doi.org/10.4271/2014-01-1479.

[18] Orhan, O., Haffner-Staton, E., La Rocca, A., Fay, M. "Characterisation of flame-generated soot and soot in oil using electron tomography volume reconstructions and comparison with traditional 2D-TEM measurements" Tribology International, 104, 272-284, 2016.

[19] Okada, K., Heintzenberg, J., Kai, K.i Qin, Y. Shape of atmospheric mineral particles collected in three Chinese arid-regions, Geophysical Research Letters, 28, 16: 3123-3126, 2001.

[20] Malloy A., and Carr, B. "Nano Particle Tracking Analysis - The Halo System," Part. Part. Syst. Charact., 23, 197-204, 2006.

[21] Growney, D.J., Mykhaylyk, O.O., Middlemiss, L., Fielding, L.A., et.al. "Is CB A Suitable Model Colloidal Surrogate for Diesel Soot?", Langmuir 31(38), 10358-10369, 2015.

\section{CONTACT INFORMATION}

Soot Diagnostics Suite

Engine Research Group

University of Nottingham

Contact: Dr Antonino La Rocca

antonino.larocca@nottingham.ac.uk

\section{ACKNOWLEDGMENTS}

The authors are grateful to the Nanoscale and Microscale Research Centre (nmRC) at the University of Nottingham for providing access to instrumentation. The authors wish to thank Ephraim Haffner-Staton (University of Nottingham) for practical guidance and Alexander Michlberger (Lubrizol Ltd) for his contributions to the project.

\section{DEFINITIONS/ABBREVIATIONS}

TEM

Transmission Electron Microscopy

NTA

Nanoparticle Tracking Analysis

StD

Standard Deviation

CB

Carbon Black

Page 8 of 8 